\title{
Primary Prevention Using Cholesterol-Lowering Medications in Patients Meeting New Treatment Guidelines: A Retrospective Cohort Analysis
}

\author{
Xue Han, MS; D. Steven Fox, MD, MSc; Michelle Chu, PharmD, CDE, BCACP; \\ J. Samantha Dougherty, PhD; and Jeffrey McCombs, PhD
}

\begin{abstract}
BACKGROUND: The American College of Cardiology and American Heart Association (ACC/AHA) issued new cholesterol treatment guidelines in 2013. Two of the groups designated for primary prevention were analyzed: patients with a low-density lipoprotein cholesterol (LDL-C) level $\geq 190 \mathrm{mg}$ per $\mathrm{dL}$ and diabetic patients aged 40-75 years.

OBJECTIVE: To estimate the effects of primary prevention as specified in the 2013 guidelines on cardiovascular event risk and cost.

METHODS: Primary prevention patients were identified using laboratory and diagnostic data for Humana members from 2007 to 2013. Potential study patients were classified into 3 risk groups: elevated LDL-C, diabetes, and elevated LDL-C and diabetes. Patients receiving cholesterol-lowering medications before their index date were excluded. Eligible patients were divided into 2 treatment groups: (1) primary prevention patients who initiated treatment before experiencing any cardiovascular disease (CVD)-related event, and (2) patients who either did not initiate treatment until after experiencing a CVD event or never initiated treatment. The associations between initiating cholesterol-lowering medications for primary prevention and the risk for acute myocardial infarction, stroke, coronary angioplasty, or coronary artery bypass graft surgery were estimated using Cox proportional hazards models. The effect of primary prevention on health care costs was estimated using generalized linear models.
\end{abstract}

RESULTS: 91,066 patients met study selection criteria. Primary prevention rates were the lowest in diabetic patients $(35 \%)$, who were newly designated for treatment in the $\mathbf{2 0 1 3}$ guidelines. Primary prevention rates were higher for patients designated for treatment under earlier guidelines: $65 \%$ for patients with elevated LDL-C and $78 \%$ for the combined LDL-C and diabetes group. Primary prevention treatment was associated with significant reductions in cardiovascular event risk (up to $37 \%$ ) and lower total allcause costs (by \$673) in the first post-index year.

CONCLUSIONS: Initiating cholesterol-lowering medications for primary prevention, as specified in the ACC/AHA 2013 guidelines, for patients with high LDL-C and diabetes is associated with reduced CVD event risks and lower health care costs.

J Manag Care Spec Pharm. 2018;24(11):1087-85

Copyright $\odot 2018$, Academy of Managed Care Pharmacy. All rights reserved.

\section{What is already known about this subject}

The 2013 American College of Cardiology and American Heart Association cholesterol treatment guidelines expanded primary prevention to patients aged 40-70 years who have diabetes and no other known cardiovascular risks, while increasing the minimum low-density lipoprotein cholesterol thresholds for treatment.

Although the average intensity of individual patient treatment increased after publication of the new guidelines, the overall rate of primary prevention using cholesterol-lowering medication among the new benefit groups did not change.

\section{What this study adds}

Updated guidelines expanded the number of patients with diabetes who were recommended for primary prevention treatment using cholesterol-lowering therapy.

The initiation of primary prevention treatment significantly reduced the risk and costs of cardiovascular events, as measured over 1 year.

B efore 2013, cholesterol-lowering treatment, as defined by guidelines in the Third Adult Treatment Panel (ATP III), was indicated for patients who had abnormally high levels of low-density lipoprotein cholesterol (LDL-C), concomitant with other risk factors such as coronary heart disease, diabetes, tobacco use, and hypertension. ${ }^{1}$ In 2013, the American College of Cardiology and American Heart Association (ACC/AHA) issued new joint guidelines that recommended cholesterollowering medication for primary or secondary prevention of atherosclerotic cardiovascular disease (ASCVD) for 4 benefit groups: Primary Prevention

- Patients aged $\geq 21$ years with LDL-C levels $\geq 190 \mathrm{mg}$ per dL (high LDL-C group).

- Patients with either type 1 or type 2 diabetes, aged 40-75 years, with LDL-C of 70-189 mg per dL (diabetes group).

- Patients with a 10 -year ASCVD risk score $\geq 7.5 \%$. (Note that patients falling into this risk group were not included in our analytic sample because insufficient data (e.g., on smoking and blood pressure) were available in the paid claims database to calculate risk scores). 


\section{Primary Prevention Using Cholesterol-Lowering Medications in Patients Meeting New Treatment Guidelines: A Retrospective Cohort Analysis}

\section{Secondary Prevention}

- Patients aged $\geq 21$ years with clinical evidence of ASCVD. ${ }^{1}$

The 2013 ACC/AHA guidelines were derived by synthesizing meta-analyses, cohort studies, and randomized controlled trials. ${ }^{2}$ Those studies demonstrated that primary and secondary prevention with cholesterol-lowering treatment, specifically statins, may reduce the incidence of atherosclerotic cardiovascular events in patients previously diagnosed with cardiovascular diseases (CVD), diabetes, a high LDL-C level, or an elevated ASCVD risk score. Unsurprisingly, subsequent research has reported that the 2013 ACC/AHA cholesterol treatment guidelines have significantly increased the number of high-intensity statin users. ${ }^{3-7}$ Guideline implementation may also improve patient outcomes by discouraging patients from delaying treatment until after a cardiac or hospitalization event occurs. ${ }^{8-14}$ However, other studies have found that the overall rates of primary and secondary prevention using cholesterol-lowering medication among the new benefit groups did not change. ${ }^{15-17}$ Furthermore, some studies indicated that the risk-calculator used in the new guidelines may systematically overestimate ASCVD risk. Those latter results raise questions on whether these newly identified primary prevention patients are truly "at risk" and thus require treatment. ${ }^{18-20}$ More research is needed using real-world data to clarify that debate, specifically by documenting whether additional clinical benefits can be expected from the expanded primary prevention guidelines. ${ }^{21,22}$

The objective of this study was to estimate the effect of initiating primary prevention treatment with cholesterol-lowering medications on the risk of CVD events and on health care costs.

Two groups designated for primary prevention under the 2013 guidelines were included in this analysis: patients with elevated LDL-C level and patients with diabetes. An additional analysis on the effects of initiating secondary prevention treatment was undertaken separately. This study used historical data that included patients who never initiated cholesterollowering medication for primary prevention and patients who delayed therapy until after experiencing a CVD event. Both groups of patients, neither of which initiated primary prevention using cholesterol-lowering medications, were needed to measure the potential benefits of initiating cholesterol-lowering therapy for primary prevention after reclassification under the 2013 guidelines.

\section{Methods}

\section{Data Sources}

This was a retrospective cohort analysis using data derived from the Humana claims database covering January 1, 2007, to June 30,2013 , the 7-year period immediately before the publication of the 2013 ACC/AHA guidelines. The Humana claims database is a national and longitudinal database covering commercial and Medicare Advantage enrollees. The data include medical claims, pharmacy claims, and lab results for a subsample of individuals. These data can be used to derive relatively complete diagnostic and drug utilization profiles, fairly accurately reflecting the patient's health status at specific points in time.

\section{Study Cohort}

Study participants met the 2013 ACC/AHA eligibility guidelines for primary prevention using cholesterol-lowering medications based on their diagnostic and laboratory lab value data. Two primary prevention cohorts specified in the 2013 guidelines were identified and a third hybrid "benefit" group was created for patients who fit both risk-group definitions:

- High LDL-C group: Patients who had $\geq 1$ lab claim of LDL-C, with LDL-C levels $\geq 190 \mathrm{mg}$ per dL.

- Diabetes group: Patients aged 40-75 years and with $\geq 1$ medical claim with International Classification of Diseases, Ninth Revision, Clinical Modification diabetes diagnosis codes.

- LDL-C and diabetes group: Patients with elevated LDL-C and diabetes diagnoses within 9 months.

The earliest date at which patients were identifiable as high risk because of either elevated LDL-C or diabetes was assigned as each patient's index date.

\section{Exclusion Criteria}

This study excluded those subjects with less than 12 months of continuous health plan enrollment after the index date or less than 6 months of continuous enrollment before the index date. This exclusion allowed lead-in time to develop variables correlated with the patient's health status at baseline and an at least 1-year follow-up period to measure key outcome variables. Also excluded were (a) patients with a major CVD event before the index date who should have been categorized as secondary prevention patients, (b) patients who filled or refilled a prescription for any treatment targeting either CVD or high cholesterol before the index date, (c) patients with a coronary angioplasty procedure or coronary artery bypass grafting (CABG) within 180 days following the index date, under the assumption that patients with these procedures within this short period should more properly be classified as secondary prevention candidates, and (d) patients aged younger than 21 years.

\section{Key Explanatory Variables}

The purpose of this study was to estimate the effectiveness of initiating cholesterol-lowering medications in primary prevention. Patients were defined as receiving primary prevention treatment if a cholesterol-lowering medication was initiated before any post-index CVD event. Primary prevention treatment was entered as a dichotomous variable in regressions. The comparison group consisted of individuals 


\section{Primary Prevention Using Cholesterol-Lowering Medications in Patients Meeting New Treatment Guidelines: A Retrospective Cohort Analysis}

\section{FIGURE 1 Flow Chart of Patient Selection Based on Exclusion Criteria}

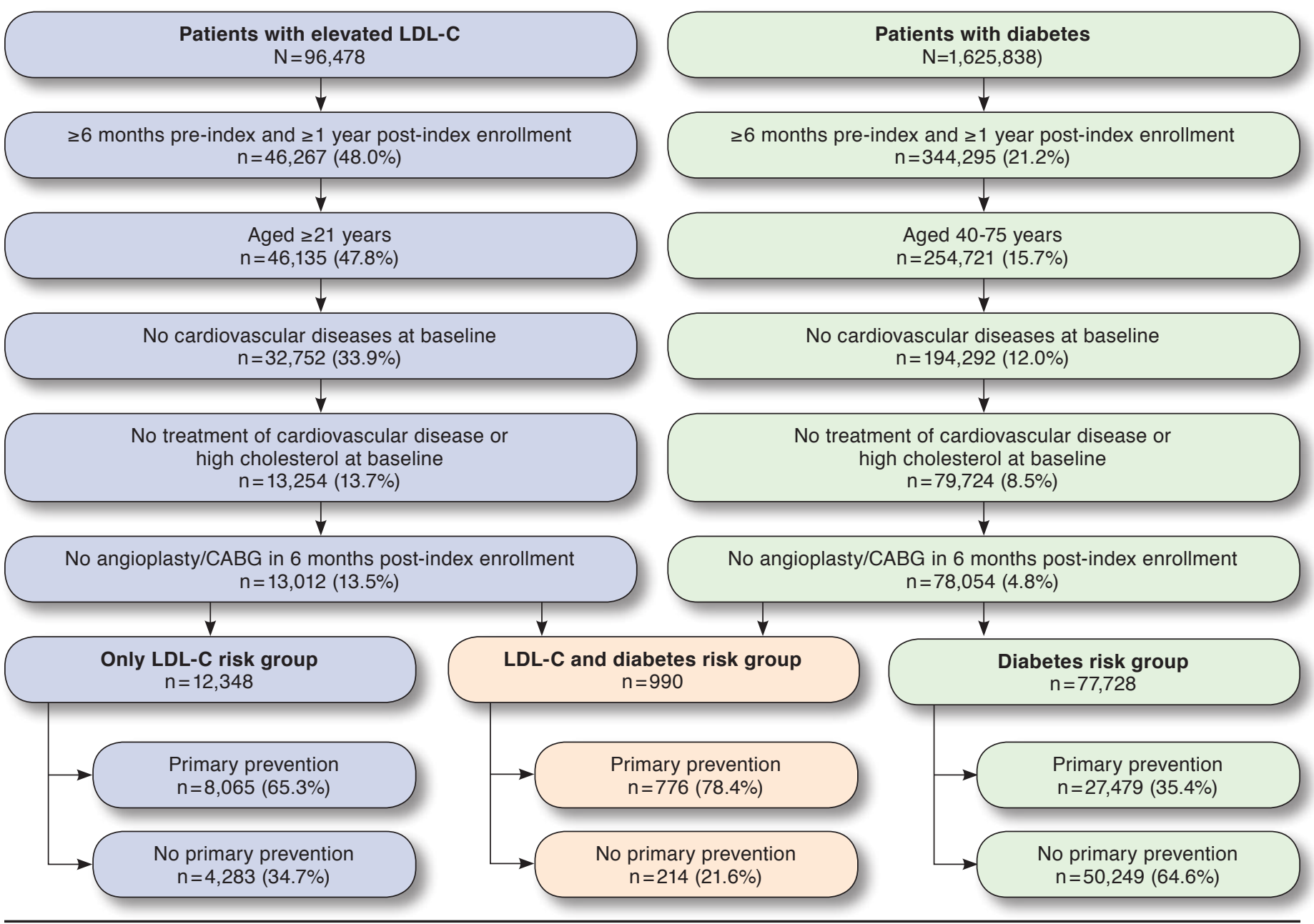

$C A B G=$ coronary artery bypass graft; $L D L-C=$ low-density lipoprotein cholesterol.

identified as candidates for primary prevention but not filling a cholesterol-lowering prescription at all (or only following their first CVD event). All available cholesterol-lowering drug therapies were used to determine if primary prevention treatment was initiated: statins, bile acid sequestrants, cholesterol absorption inhibitors, fibric acid derivatives, niacin, or omega-3 fatty acid ethyl esters to define patient treatment status. Additionally, the more specific effect of statin therapy was also analyzed as a sensitivity analysis in which statin and nonstatin medications were entered separately into the multivariable analyses.

\section{Outcomes and Other Covariates}

This analysis investigated 2 primary outcomes: (1) the occurrence of CVD-related events (i.e., acute myocardial infarction [AMI], stroke, coronary angioplasty, and $(A B G)$ at any time following the index date and (2) all-cause health care costs over the first year following the index date. Cardiovascular events were selected because they reflect the expected consequences of unmanaged hyperlipidemia. Health care costs were measured over the first year following the patient's index date and were specified by type of service (medical, pharmacy, and total).

The covariates used in the statistical models included age, gender, race, region, benefit group, health plan type, statin or nonstatin cholesterol-lowering drug, diagnostic history (infection, endocrine disorders, diseases of blood, mental disorders, nervous system, hypertension, circulatory system, respiratory system, digestive system, or genitourinary system anomaly), history of prescription drug use (antiobesity, antiinflammatory, painkiller, antiviral, antiasthmatic, antiseizure, antidepressants, antidiabetic, antihypertensive, antiparkinson, antihistamines, antimetabolism, anticoagulants, hypnotic, ophthalmic, antithyroid, antiulcer, or anticholinergic), previous 


\section{Primary Prevention Using Cholesterol-Lowering Medications in Patients \\ Meeting New Treatment Guidelines: A Retrospective Cohort Analysis}

\begin{tabular}{|c|c|c|c|}
\hline Characteristics & $\begin{array}{c}\text { Primary } \\
\text { Prevention } \\
\mathrm{n}=36,320 \\
(39.9 \%)\end{array}$ & $\begin{array}{c}\text { No Primary } \\
\text { Prevention } \\
\mathbf{n}=54,746 \\
(60.1 \%)\end{array}$ & $P$ Value \\
\hline \multicolumn{4}{|l|}{ Age at year of index date, $\%$} \\
\hline $21-44$ years & 7.3 & 8.2 & $<0.0001$ \\
\hline $45-54$ years & 19.9 & 20.7 & 0.0062 \\
\hline $55-64$ years & 22.0 & 22.0 & 0.9219 \\
\hline $65-74$ years & 46.1 & 45.0 & 0.0020 \\
\hline Older than 75 years & 4.7 & 4.2 & $<0.0001$ \\
\hline \multicolumn{4}{|l|}{ Sex $\%$} \\
\hline Men & 42.7 & 43.7 & 0.0020 \\
\hline \multicolumn{4}{|l|}{ Risk group, \% } \\
\hline Only high LDL-C & 22.2 & 7.8 & $<0.0001$ \\
\hline Only diabetes & 75.7 & 91.8 & $<0.0001$ \\
\hline LDL-C and diabetes & 2.1 & 0.4 & $<0.0001$ \\
\hline \multicolumn{4}{|l|}{ Race, \% } \\
\hline White & 51.0 & 49.6 & $<0.0001$ \\
\hline Black & 9.9 & 9.4 & 0.0084 \\
\hline Asian & 0.6 & 0.6 & 0.2905 \\
\hline Hispanic & 1.5 & 1.2 & 0.0002 \\
\hline Unknown & 36.7 & 39.1 & $<0.0001$ \\
\hline \multicolumn{4}{|l|}{ Region, \% } \\
\hline Midwest & 21.8 & 23.1 & $<0.0001$ \\
\hline Northeast & 1.2 & 1.5 & 0.0005 \\
\hline South & 67.1 & 64.7 & $<0.0001$ \\
\hline West & 8.3 & 9.0 & 0.0004 \\
\hline Unknown & 1.6 & 1.7 & 0.3291 \\
\hline \multicolumn{4}{|l|}{ Health plan, \% } \\
\hline $\mathrm{HMO}$ & 27.9 & 23.6 & $<0.0001$ \\
\hline PFFS & 23.6 & 23.7 & 0.7191 \\
\hline POS & 6.7 & 6.8 & 0.7375 \\
\hline $\mathrm{PPO}$ & 29.1 & 32.6 & $<0.0001$ \\
\hline Other & 12.7 & 13.4 & 0.0013 \\
\hline \multicolumn{4}{|l|}{ Prior utilization, 6 months } \\
\hline Hospital admission, $\%$ & 3.2 & 5.4 & $<0.001$ \\
\hline Medical costs, \$, mean (SD) & $1,089 \quad(3,235)$ & $1,420 \quad(4,403)$ & $<0.001$ \\
\hline Pharmacy costs, $\$$, mean (SD) & $563(1,389)$ & $646 \quad(1,913)$ & $<0.001$ \\
\hline Total costs, $\$$, mean (SD) & $2,128 \quad(7,126)$ & $3,198(11,555)$ & $<0.001$ \\
\hline \multicolumn{4}{|c|}{$\begin{array}{l}\text { HMO = health maintenance organization; } L D L-C=\text { low-density lipoprotein } \\
\text { cholesterol; } P F F S=\text { private fee-for-service; } P O S=\text { point-of-service; } P P O=\text { preferred } \\
\text { provider organization; } S D=\text { standard deviation. }\end{array}$} \\
\hline
\end{tabular}

hospital admission, and health care cost at baseline, measured over the 6 months before the patient's index date.

\section{Statistical Analysis}

All of the descriptive statistics comparing patient baseline characteristics across treatment status used either the Pearson's chi-square test or a t-test. The association between primary prevention and the risk of cardiovascular events was analyzed using Cox proportional hazards models. Costs for medical, pharmacy, and total health care services were analyzed using generalized linear model procedures.

Three sensitivity analyses were also run to test the robustness of results. The first sensitivity analysis estimated the effects of primary prevention treatment using statin and nonstatin drugs separately. The second sensitivity analysis added dummy variables into the primary risk analyses for the AMI and stroke models which specifically indicated the occurrence of CABG or coronary angioplasty procedures before the occurrences of any other CVD event, on the assumption that these procedures are correlated with the patient's baseline severity of illness. The third sensitivity analysis reintroduced into the analysis all of the patients with CABG or coronary angioplasty procedures within 180 days following their index date. Analyses were performed using the SAS System for Unix 9.3 (SAS Institute, Cary, NC).

\section{Results}

Selection of patients for the study is outlined in Figure 1. It is difficult to project the extent to which the new 2013 guidelines expanded the total population of patients designated for primary prevention, relative to previous guidelines. For example, all of the high LDL-C group found in Figure 1 meet the LDL-C requirements for primary prevention as specified under the ATP III guidelines. However, this high LDL-C group may be underestimated because LDL-C is intended to identify patients who likely have familial hypercholesterolemia, which cannot be identified here (because of lack of genetic screening data). Conversely, patients with diabetes were designated for primary prevention in the 2013 ACC/AHA guidelines based solely on that diagnosis and age, without necessarily having other CVD risk factors (i.e., family history, hypertension, history of tobacco use, dyslipidemia, or albuminuria) as required under the previous American Diabetes Association (ADA) guidelines. Therefore, the 2013 guidelines likely increased the number of patients with diabetes designated for primary prevention.

Data were available that somewhat clarified this issue: In our sample, $52.5 \%$ of patients with diabetes have at least 1 other identifiable CVD risk factor (i.e., previous history of hypertension, dyslipidemia, or albuminuria) that would have designated these patients for treatment under previous ADA guidelines. This proportion would likely increase if we had data on smoking status. Even if $60 \%$ of the diabetes group would have been designated for treatment under older guidelines, our results imply that full implementation of the 2013 guidelines would considerably increase the number of patients with diabetes eligible for primary prevention using cholesterol-lowering drugs. The high LDL-C risk group experienced significantly higher rates of primary prevention treatment during 2007-2013 than did the diabetes group, $65 \%$ versus $35 \%$, respectively (Figure 1 ). This low treatment rate in the diabetes group likely reflects that the new 2013 guidelines expanded primary prevention 


\begin{tabular}{l|c}
\hline \multicolumn{1}{c}{ TABLE 2 } & $\begin{array}{c}\text { Frequency of Cholesterol-Lowering } \\
\text { Medications by Treatment Class }\end{array}$ \\
\hline Cholesterol-Lowering Medication & Percentage \\
\hline Statins & 88.14 \\
\hline Atorvastatin & 14.22 \\
\hline Fluvastatin & 0.10 \\
\hline Lovastatin & 6.63 \\
\hline Pitavastatin & 0.04 \\
\hline Pravastatin & 15.00 \\
\hline Rosuvastatin & 9.12 \\
\hline Simvastatin & 40.85 \\
\hline Combination & 2.18 \\
\hline Nonstatins & 11.86 \\
\hline Bile acid sequestrants & 1.25 \\
\hline Cholestyramine & 1.16 \\
\hline Colesevelam & 0.24 \\
\hline Colestipol & \\
\hline Fibric acid derivatives & 4.29 \\
\hline Fenofibrate & 2.45 \\
\hline Gemfibrozil & 1.09 \\
\hline Ezetimibe & 1.39 \\
\hline Niacin & \\
\hline &
\end{tabular}

to patients with diabetes who were not designated for primary prevention during the data period (2007-2013).

The unadjusted comparison of patient characteristics at baseline between patients with and without primary prevention treatment, are shown in Table 1. Most patients were aged older than 65 years in each treatment group, but patients tended to be clustered in the 65-74 age group. Men were less likely than women to initiate primary prevention treatment, as were patients in the diabetes benefit group. Racial and geographic differences were small, although in this study most patients were Caucasian and from the southern United States. Additionally, most patients who initiated primary prevention treatment were enrolled in an health maintenance organization), whereas patients without primary prevention were covered by a preferred provider organization insurance plan. Primary prevention patients also displayed lower rates of previous hospitalization and lower costs over the 6-month period before being indexed as high risk.

Table 2 shows the frequency of patients' initial prescription of cholesterol-lowering medications by individual drugs. In total, $88 \%$ of patients initiated treatment using statins as their cholesterol-lowering medication of choice. Half of those patients were specifically prescribed simvastatin. In addition, patients treated with nonstatins used fibronates (6.74\%) as their preferred drug for primary prevention treatment.

Table 3 presents unadjusted data for the study outcomes, stratified by primary prevention status. The probability of having a stroke was significantly lower among patients initiating primary prevention, whereas primary prevention patients

\section{TABLE 3 Patient Outcomes by Treatment Status}

\begin{tabular}{|c|c|c|c|}
\hline All Risk Groups & $\begin{array}{c}\text { Primary } \\
\text { Prevention } \\
\mathbf{n}=36,320 \\
(39.9 \%)\end{array}$ & $\begin{array}{c}\text { No Primary } \\
\text { Prevention } \\
\mathbf{n}=54,746 \\
(60.1 \%)\end{array}$ & $P$ Value \\
\hline \multicolumn{4}{|l|}{ Proportions of events, n (\%) } \\
\hline Stroke & 8.0 & 9.5 & $<0.0001$ \\
\hline AMI & 2.5 & 2.6 & 0.3223 \\
\hline Coronary angioplasty & 2.0 & 1.7 & 0.0004 \\
\hline CABG & 0.9 & 0.6 & $<0.0001$ \\
\hline \multicolumn{4}{|c|}{ Time to events, days, mean (SD) } \\
\hline Time to stroke & 1,130 & $(523)$ & $<0.0001$ \\
\hline Time to AMI & $1,169 \quad(569)$ & $(524)$ & $<0.0001$ \\
\hline Time to angioplasty & $1,170 \quad(568)$ & $(523)$ & $<0.0001$ \\
\hline Time to CABG & $1,176 \quad(569)$ & $(525)$ & $<0.0001$ \\
\hline \multicolumn{4}{|c|}{ Health care admission over first-year post-index enrollment } \\
\hline Hospital admission, $\mathrm{n}(\%)$ & 13.4 & 16.4 & $<0.0001$ \\
\hline \multicolumn{4}{|c|}{ Health care cost over first-year post-index enrollment, mean \$ (SD) } \\
\hline Medical & $6,013(15,815)$ & $7,865(23,529)$ & $<0.0001$ \\
\hline Pharmacy & $1,732 \quad(3,150)$ & $1,598 \quad(4,200)$ & $<0.0001$ \\
\hline Total & $7,745(16,638)$ & $9,463(24,540)$ & $<0.0001$ \\
\hline
\end{tabular}

did not exhibit a significantly different unadjusted risk of AMI. Conversely, primary prevention patients had higher rates of coronary angioplasty and CABG relative to patients without primary prevention, even after excluding patients undergoing these procedures within 180 days following their index date. However, primary prevention patients did experience a longer average delay between their index date and an event date/end of data than did patients without primary prevention. The average time to event ranged from 1,130 to 1,180 days for the 4 outcome events in the primary prevention group, versus from 900 to 980 days in the group without primary prevention. Finally, primary prevention patients experienced lower hospital rates in the first post-index year (13\%) compared with "no primary prevention" patients (16\%). Unsurprisingly, the primary prevention population experienced lower average overall costs than patients not receiving primary prevention, despite having higher pharmacy costs.

Results from the multivariable analyses, adjusting for other risk factors, are presented in Table 4. Cox proportional hazard regression models were used to estimate hazard ratios of stroke, AMI, coronary angioplasty, and CABG, after adjusting for age, gender, race, region, benefit group, health plan type, diagnostic history, history of prescription drug use, previous hospital admission, and health service costs. The results from Model 1 indicate that primary prevention treatment was significantly associated with a reduced risk of stroke, AMI, and coronary angioplasty, whereas its association with CABG was insignificant. That is, initiating cholesterol-lowering treatment 


\section{Primary Prevention Using Cholesterol-Lowering Medications in Patients Meeting New Treatment Guidelines: A Retrospective Cohort Analysis}

\section{TABLE 4 Summary of Estimated Effects of Primary Prevention and Risk Group Affiliation}

\begin{tabular}{|c|c|c|c|c|c|c|c|c|c|c|}
\hline \multicolumn{11}{|c|}{ Clinical Outcomes } \\
\hline & \multicolumn{3}{|c|}{ Stroke } & \multicolumn{3}{|c|}{ AMI } & \multicolumn{2}{|c|}{ Coronary Angioplasty } & \multicolumn{2}{|r|}{ CABG } \\
\hline & HR & \multicolumn{2}{|c|}{$95 \%$ CI } & \multicolumn{2}{|c|}{ HR } & $95 \%$ CI & HR & $95 \%$ CI & HR & $95 \%$ CI \\
\hline \multicolumn{11}{|l|}{ Cox model $1, \mathrm{n}=91,066$} \\
\hline Primary prevention & $0.63^{a}$ & \multicolumn{2}{|c|}{$0.60-0.66$} & \multicolumn{2}{|c|}{$0.73^{a}$} & $0.66-0.79$ & $0.86^{\mathrm{a}}$ & $0.78-0.95$ & 1.07 & $0.92-1.26$ \\
\hline High LDL-C group vs. diabetes group & $1.38^{\mathrm{a}}$ & \multicolumn{2}{|c|}{$1.28-1.47$} & \multicolumn{2}{|c|}{$1.37^{\mathrm{a}}$} & $1.20-1.56$ & $1.58^{\mathrm{a}}$ & $1.36-1.84$ & $1.50^{\mathrm{a}}$ & $1.17-1.92$ \\
\hline LDL-C and diabetes group vs. diabetes group & $1.48^{\mathrm{a}}$ & \multicolumn{2}{|c|}{$1.23-1.79$} & \multicolumn{2}{|c|}{$1.82^{\mathrm{a}}$} & $1.31-2.53$ & $1.98^{\mathrm{a}}$ & $1.37-2.86$ & $2.53^{\mathrm{a}}$ & $1.50-4.26$ \\
\hline \multicolumn{11}{|c|}{ Cox model 2: statins and nonstatins effects estimated separately, $\mathrm{n}=91,066$} \\
\hline Primary prevention: statins & $0.63^{a}$ & \multicolumn{2}{|c|}{$0.60-0.66$} & \multicolumn{2}{|c|}{$0.73^{\mathrm{a}}$} & $0.66-0.80$ & $0.85^{\mathrm{a}}$ & $0.76-0.94$ & 1.09 & $0.93-1.29$ \\
\hline Primary prevention: nonstatins & $0.70^{\mathrm{a}}$ & \multicolumn{2}{|c|}{$0.63-0.77$} & \multicolumn{2}{|c|}{$0.76^{\mathrm{a}}$} & $0.63-0.92$ & 1.03 & $0.84-1.25$ & 0.994 & $0.71-1.39$ \\
\hline High LDL-C group vs. diabetes group & $1.38^{\mathrm{a}}$ & 1.2 & 3-1.47 & 1.3 & & $1.19-1.56$ & $1.59^{\mathrm{a}}$ & $1.37-1.85$ & $1.49^{\mathrm{a}}$ & $1.16-1.91$ \\
\hline LDL-C and diabetes group vs. diabetes group & $1.48^{\mathrm{a}}$ & 1.2 & $3-1.79$ & 1.8 & & $1.55-2.10$ & $1.99^{\mathrm{a}}$ & $1.38-2.87$ & $2.52^{\mathrm{a}}$ & $1.49-4.24$ \\
\hline Cox model 3: using CABG and angioplasty as & an indicator & f sev & erity of & ness & $\mathrm{at} b$ & eline, $n=91$ & 66 & & & \\
\hline Primary prevention & $0.63^{a}$ & 0.6 & -0.66 & 0.72 & & $0.66-0.79$ & & & & \\
\hline High LDL-C group vs. diabetes group & $1.38^{\mathrm{a}}$ & 1.2 & $3-1.47$ & 1.37 & & $1.20-1.57$ & & & & \\
\hline LDL-C and diabetes group vs. diabetes group & $1.48^{\mathrm{a}}$ & & $2-1.79$ & 1.8 & & $1.30-2.52$ & & & & \\
\hline Cox model 4: analysis on all patients, $n=91,6$ & & & & & & & & & & \\
\hline Primary prevention & $0.63^{a}$ & 0.6 & -0.66 & 0.68 & & $0.63-0.74$ & $0.78^{\mathrm{a}}$ & $0.71-0.85$ & 1.00 & $0.87-1.16$ \\
\hline High LDL-C group vs. diabetes group & $1.39^{\mathrm{a}}$ & & -1.50 & 1.4 & & $1.27-1.63$ & $1.68^{\mathrm{a}}$ & $1.47-1.92$ & $1.58^{\mathrm{a}}$ & $1.28-1.96$ \\
\hline LDL-C and diabetes group vs. diabetes group & $1.49^{\mathrm{a}}$ & & -1.80 & 1.8 & & $1.31-2.49$ & $1.98^{\mathrm{a}}$ & $1.41-2.78$ & $2.62^{\mathrm{a}}$ & $1.65-4.16$ \\
\hline & All- & Caus & Cost $\mathrm{C}$ & come & es A & r Year 1 & & & & \\
\hline & & lical & Costs & & & Drug & Costs & & Total C & Costs \\
\hline & $\begin{array}{c}\text { Estimated Ef } \\
\text { in } \$\end{array}$ & & $95 \%$ & & & $\begin{array}{l}\text { nated Effect } \\
\text { in } \$\end{array}$ & $95 \% \mathrm{CI}$ & $\begin{array}{r}\text { Estimate } \\
\text { in } \\
\end{array}$ & Effect & $95 \% \mathrm{CI}$ \\
\hline GLM model, $\mathrm{n}=91,066$ & & & & & & & & & & \\
\hline Primary prevention & $-673^{a}$ & & -936 & & & $219^{a}$ & $170-267$ & -45 & & $-725--184$ \\
\hline High LDL-C group vs. diabetes group & $-674^{a}$ & & $-1,064$ & 84 & & $-154^{a}$ & $-226--82$ & -82 & & $-1,230--427$ \\
\hline LDL-C and diabetes group vs. diabetes group & $1,676^{\mathrm{a}}$ & & 470 & 881 & & 96 & $-127-319$ & 1,77 & & $531-3,012$ \\
\hline
\end{tabular}

before any cardiac event decreased the likelihood of stroke by $37 \%$ and AMI by 27\%. Results from Model 1 also documented that the high LDL-C and LDL-C and diabetes risk groups both experienced a higher adjusted risk of all events, relative to patients with diabetes only.

Additional results from 3 sensitivity analyses are presented as Model 2, 3, and 4. Model 2 separately estimated the effect of initiating primary prevention treatment using statin versus nonstatin therapy. Unsurprisingly, statin therapies outperformed nonstatin therapies with respect to the risk reduction associated with primary prevention; however, the differences between the 2 drug classes was small and not statistically significant. Model 3 added dummy variables that indicated post-index coronary angioplasty or CABG had occurred before other CVD outcomes. These explanatory variables were used to control for possible differences in baseline severity of illness. The association between primary prevention and the risk of stroke and AMI was unchanged. Model 4 added back into the analysis those patients with a CABG or angioplasty within 180 days following their index date who were excluded from
Model 1. The association of primary prevention with cardiovascular events, across all 3 risk groups, remained consistent with the results from Model 1. Initiating primary prevention still reduced the risk of stenting and CABG and reduced total costs in the first year.

The relationship between primary prevention and health care costs was estimated using generalized linear models (Table 4). Primary prevention was associated with a reduced total cost per patient of $\$ 673$ in the first year following the index date, despite the prescription drug costs for these patients having increased by $\$ 219$. Patients in the high LDL-C risk group were less costly to treat in the first post-index year than patients in the diabetes group, despite being at higher risk for CVD events.

\section{Discussion}

The 2013 ACC/AHA guidelines still have significant untapped potential to improve clinical outcomes and reduce health care costs. Several of our results are particularly worthy to note. First, they imply that the ACC/AHA guidelines likely increased the total number of patients with diabetes meeting recommendations 


\section{Primary Prevention Using Cholesterol-Lowering Medications in Patients Meeting New Treatment Guidelines: A Retrospective Cohort Analysis}

for primary prevention treatment with cholesterol-lowering therapy. Although over 52\% of our diabetic sample had other evidence of CVD risks, and some additional patients with diabetes in our sample may smoke, ${ }^{23}$ we conclude that the 2013 ACC/AHA guidelines will expand the total number of patients for whom primary prevention is recommended. Moreover, those additional patients appear likely to benefit from primary prevention, with better health outcomes and lower costs.

Second, our results also document that the high LDL-C group, while still benefiting significantly from primary prevention, experienced a higher overall risk of CVD-related events relative to the diabetes group, whereas diabetic patients cost more to treat over the first post-index year. The rate of primary prevention treatment in the high LDL-C risk group was also only $65 \%$, also suggesting significant room for improvement. In our study, the primary prevention treatment rate for the diabetes risk group was only $35 \%$, likely because patients with diabetes with normal LDL-C levels had not yet been recommended for treatment under previous guidelines. However, the finding that a significant proportion of patients with elevated ASCVD risk failed to initiate primary prevention treatment is consistent with earlier studies., ${ }^{9,24}$ The 2013 guidelines designated additional candidates for cholesterol-lowering therapy, and our results indicate that they may indeed benefit from primary prevention treatment. Perhaps more important, this study also demonstrated that primary prevention treatment was associated with significant reductions in CVD event risk and significantly lower health care costs. Those results proved robust to sensitivity analyses that controlled for the severity of cardiac problems, even after the index diagnosis.

In our analysis, primary prevention patients did not experience a significantly different unadjusted risk of AMI, which conflicts with the conclusion from some clinical trials of CVD. ${ }^{25,26}$ However, after adjusting for patients' other characteristics, primary prevention was associated with a significant reduction in AMI risk, consistent with previous results. By contrast, our unadjusted and adjusted results demonstrated that primary prevention with cholesterol-lowering medications can significantly reduce the risk of stroke. ${ }^{27}$

Finally, these results likely represent an underestimate of the potential benefits of primary prevention because not all treated patients received statins, and the dose of statin therapy was not assessed. Primary prevention patients were therefore likely undertreated, on average, by current guidelines.

\section{Limitations}

Several limitations of this study require discussion. Treatment selection bias may exist in any study that uses real-world data to compare alternative treatments. Patients who initiated primary prevention treatment may also differ in other important but unmeasured ways from patients who delayed primary prevention until after an event or who did not initiate primary prevention treatment during the observation period. Patients who were intolerant to cholesterol-lowering medication could also not be identified, because of the lack of electronic medical records. The primary defense against potential treatment selection bias, arising from the nonrandom initiation of primary prevention, is to more fully document the observable characteristics of the patients in the study. This was the approach taken here, as evidenced by the multiple baseline characteristics included in our statistical models. Other more elegant statistical methods have also been developed, such as instrumental variable and Heckman selection regression methods. These approaches were not applied in this study because of the low probability that any unobserved factors could be a main source of the highly significant effects estimated here for patients using primary prevention.

Another risk group, patients with high 10-year ASCVD risk scores, is also recommended for primary prevention under 2013 guidelines. However, patients with high ASCVD risk scores could not be identified because smoking status and blood pressure was not reliably available in the Humana data. Thus, that treatment group was not included in the analysis. Therefore, this study cannot estimate the overall extent of users eligible for primary prevention according to the 2013 guidelines.

CVD is a leading cause of death in the United States, therefore, mortality is also an important outcome that should be considered. We could not estimate the association between the primary prevention treatment and cardiac mortality, since that mortality information was not available in Humana data. Further analysis is also needed to document the effect of duration of therapy on CVD outcomes and costs. For example, Grembowski et al. (2016) found that the cumulative statin use over time was correlated cumulatively with lower rates of cardiovascular death, stroke and AMI but had no cumulative effect on costs. ${ }^{21}$

\section{Conclusions}

Fuller implementation of the 2013 guidelines would expand primary prevention to a large number of patients at high risk for newly defined diabetes. Our results indicate that patients with diabetes within this expanded eligible population could benefit significantly from primary prevention. Moreover, we found that primary prevention using cholesterol-lowering treatment improved 1-year post-index costs and clinical outcomes at any post-index time in patients with both high LDL-C and diabetes, even without any consideration of long-term adherence to treatment. From every stakeholder perspectivepatient, payer, and policy-it seems clear that the benefits of primary prevention justify greater efforts to treat a larger proportion of eligible patients. 


\section{Primary Prevention Using Cholesterol-Lowering Medications in Patients Meeting New Treatment Guidelines: A Retrospective Cohort Analysis}

\section{Authors}

XUE HAN, MS; D. STEVEN FOX, MD, MSc; and JEFFREY MCCOMBS, PhD, Department of Pharmaceutical and Health Economics, School of Pharmacy, Leonard Schaeffer Center for Health Policy and Economics, University of Southern California, Los Angeles. MICHELLE CHU, PharmD, CDE, BCACP, Titus Family Department of Clinical Pharmacy, School of Pharmacy, University of Southern California, Los Angeles. J. SAMANTHA DOUGHERTY, PhD, Policy and Research Department, Pharmaceutical Research and Manufacturers of America, Washington, DC.

AUHOR CORRESPONDENCE: Xue Han, MS, Department of Pharmaceutical and Health Economics, School of Pharmacy, Leonard Schaeffer Center for Health Policy and Economics, University of Southern California, 635 Downey Way, VPD, Rm 312, Los Angeles, CA 90089. Tel.: 213.309.9719; E-mail: xuehan@usc.edu.

\section{DISCLOSURES}

No outside funding supported this study. Han received fellowship support from the Pharmaceutical Research and Manufacturers Association Foundation (PhRMA) during the conduct of this study. Dougherty is employed by PhRMA. The authors have nothing to disclose.

\section{REFERENCES}

1. National Cholesterol Education Program (NCEP). Third report of the expert panel on detection, evaluation, and treatment of high blood cholesterol in adults (Adult Treatment Panel III). NIH Publication 02-5215. Final report. September 2002. Available at: https://www.nhlbi.nih.gov/files/docs/ resources/heart/atp-3-cholesterol-full-report.pdf. Accessed August 24, 2018 2. Stone NJ, Robinson JG, Lichtenstein AH, et al. 2013 ACC/AHA guideline on the treatment of blood cholesterol to reduce atherosclerotic cardiovascular risk in adults: a report of the American College of Cardiology/American Heart Association Task Force on Practice Guidelines. J Am Coll Cardiol. 2014:63(25):2889-934.

3. Ko MJ, Kim YJ, Park CM, et al. Applicability and potential clinical effects of 2013 cholesterol guidelines on major cardiovascular events. Am Heart J. 2015;170(3):598-605.

4. Chia YC, Lim HM, Ching SM. Does use of pooled cohort risk score overestimate the use of statin? a retrospective cohort study in a primary care setting. BMC Fam Pract. 2014;15(172):1-6.

5. Pavlovic J, Greenland P, Deckers JW, et al. Comparison of ACC/AHA and ESC guideline recommendations following trial evidence for statin use in primary prevention of cardiovascular disease results from the populationbased Rotterdam study. JAMA Cardiol. 2016;1(6):708-13.

6. Yeboah J, Sillau S, Delaney JC, et al. Implications of the new ACC/AHA cholesterol guidelines for primary atherosclerotic cardiovascular disease event prevention in a multi- ethnic cohort: MESA. Am Heart J. 2015; 169(3):387-95.

7. Maddox TM, Borden WB, Tang F et al. Implications of the 2013 ACC/ AHA cholesterol guidelines for adults in contemporary cardiovascular practice: insights from the NCDR PINNACLE Registry. J Am Coll Cardiol. 2014:64(21):2183-92

8. Fonarow GC, Ballantyne CM. In-hospital initiation of lipid-lowering therapy for patients with coronary heart disease: the time is now. Circulation. 2001;103(23):2768-70.

9. Fonarow GC, French WJ, Parsons LS, Sun H, Malmgren JA. Use of lipidlowering medications at discharge in patients with acute myocardial infarction: data from the National Registry of Myocardial Infarction 3. Circulation. 2001;103(1):38-44.
10. Sueta CA, Chowdhury M, Boccuzzi SJ, et al. Analysis of the degree of undertreatment of hyperlipidemia and congestive heart failure secondary to coronary artery disease. Am J Cardiol. 1999;83(9):1303-07.

11. Jacobson TA, Griffiths GG, Varas C, Gause D, Sung JC, Ballantyne CM. Impact of evidence-based "clinical judgment" on the number of American adults requiring lipid-lowering drug therapy based on updated NHANES III data. Arch Intern Med. 2000;160(9):1361-69.

12. Pearson TA, Laurora I, Chu H, Kafonek S, et al. The Lipid Treatment Assessment Project (L-TAP): a multicenter survey to evaluate the percentages of dyslipidemic patients receiving lipid-lowering therapy and achieving lowdensity lipoprotein cholesterol goals. Arch Intern Med. 2000;160(4):459-67.

13. Pattenden J, Watt I, Lewin RJP, Stanford N. Decision making processes in people with symptoms of acute myocardial infarction: qualitative study. BMJ. 2002;324(1006):1-5

14. Moser DK, Kimble LP, Alberts MJ, et al. Reducing delay in seeking treatment by patients with acute coronary syndrome and stroke. Circulation. 2006;114(2):168-82.

15. Tran JN, Kao TC, Caglar T, et al. Impact of the 2013 cholesterol guideline on patterns of lipid-lowering treatment in patients with atherosclerotic cardiovascular disease of diabetes after 1 year. J Manag Care Spec Pharm. 2016;8(22):901-08. Available at: https://www.jmcp.org/doi/10.18553/ jmcp.2016.22.8.901.

16. Quek RGW, Fox KM, Wang L, Li L, Gandra SR, Wong ND. A US claimsbased analysis of real-world lipid-lowering treatment patterns in patients with high cardiovascular disease risk or a previous coronary event. Am J Cardiol. 2016;117(4):495-500.

17. Smith SC. The 2013 ACC/AHA guidelines on treatment of blood cholesterol to improve cardiovascular outcomes: implications for statin use and dose vs. target. Cardiovasc Innov Appl. 2016:1(4):465-67.

18. DeFilippis AP, Young R, Carrubba CJ, et al. An analysis of calibration and discrimination among multiple cardiovascular risk scores in a modern multiethnic cohort. Ann Intern Med. 2015;162(4):266-75.

19. Kavousi M, Leening MJ, Nanchen D, et al. Comparison of application of the ACC/AHA guidelines, Adult Treatment Panel III guidelines, and European Society of Cardiology guidelines for cardiovascular disease prevention in a European cohort. JAMA. 2014;311(14):1416-23.

20. Ridker PM, Cook NR. Statins: new American guidelines for prevention of cardiovascular disease. Lancet. 2013;382(9907):1762-65.

21. Grembowski D, Ralston JD, Anderson ML. Health outcomes of population-based pharmacy outreach to increase statin use for prevention of cardiovascular disease in patients with diabetes. J Manag Care Spec Pharm. 2016;22(8):909-17. Available at: https://www.jmcp.org/doi/full/10.18553/ jmcp. 2016.22.8.909.

22. U.S. Preventive Services Task Force. Statin use for the primary prevention of cardiovascular disease in adults: US Preventive Services Task Force Recommendation Statement. JAMA. 2016;316(19):1997-2007.

23. Schipf S, Schmidt CO, Alte D. Smoking prevalence in type 2 diabetes: results of the Study of Health in Pomerania (SHIP) and the German National Health Interview and Examination Survey (GNHIES). Diabet Med. 2009;26(8):791-97.

24. Moser DK, Kimble LP, Alberts MJ, et al. Reducing delay in seeking treatment by patients with acute coronary syndrome and stroke. Circulation. 2006;114(2):168-82.

25. Scandinavian Simvastatin Survival Study Group. Randomised trial of cholesterol lowering in 4444 patients with coronary heart disease: the Scandinavian Simvastatin Survival Study (4S). Lancet. 1994;344(8934): 1383-89.

26. Sacks FM, Pfeffer MA, Moye LA, et al. The effect of pravastatin on coronary events after myocardial infarction in patients with average cholesterol levels. N Engl J Med. 1996;335(14):1001-09.

27. Everett BM, Glynn RJ, MacFadyen JG, et al. Rosuvastatin in the prevention of stroke among men and women with elevated levels of C-reactive protein: Justification for the Use of Statins in Prevention: an Intervention Trial Evaluating Rosuvastatin (JUPITER). Circulation. 2010;121(1):143-50. 